\title{
Pengontrolan Electro Conductivity pada Larutan Nutrisi Hidroponik Berbasis Arduino
}

\author{
Syafa Aprillia1, Dwiprima Elvanny Myori 2 \\ 1,2Universitas Negeri Padang \\ Jl. Prof Dr. Hamka Air Tawar, Padang \\ syafaaprillia29@gmail.com,elvannymyori@gmail.com
}

\begin{abstract}
Hydroponics is a planting pattern in agriculture without soil media and it empowers water. Water in hydroponic plants is water that contains nutrients. These nutrients must be known to the value of EC (Electro Conductivity). The problem that often occurs in farmers is the limited time to monitor hydroponic plants continuously. If the nutrient fluid is not monitored regularly and thoroughly, it can result in suboptimal plant growth in the quality of these vegetable plants. This study aims to create a control system for EC levels in hydroponic plants and to control the water level in the reservoir. This research consists of making hardware and software To measure the EC value, an EC meter sensor is used which is connected to the Arduino Uno Microcontroller as the system control center. After several experiments on this tool, all components and work systems of this tool are able to work in accordance with the research objectives. The application of an automatic system for adding nutrient fluids to hydroponic plants can make it easier for farmers to maintain and monitor hydroponic plants.
\end{abstract}

Keywords - Hydroponic, Electrical Conductivity (EC), Arduino Uno, Water Level, Valve Electric

Abstrak - Hidroponik merupakan pola cocok tanam dibidang pertanian tanpa media tanah dan memberdayakan air. Air pada tanaman hidroponik ini merupakan air yang mengandung nutrisi. Nutrisi tersebut harus diketahui kadar nilai EC (Electro Conductivity). Permasalahan yang sering terjadi pada petani yaitu keterbatasan waktu untuk memantau tanaman hidroponik secara terus menerus. Jka cairan nutrisi tidak dipantau secara rutin dan teliti, dapat mengakibatkan pertumbuhan tanaman yang tidak optimal pada kualitas tanaman sayur tersebut. Penelitian ini bertujuan untuk membuat sistem pengontrolan kadar EC pada tanaman hidroponik dan mengontrol level air pada tandon. Pada penelitian ini terdiri dari pembuatan perangkat keras dan perangkat lunak. Untuk mengukur nilai EC tersebut digunakan sensor EC meter yang terhubung dengan Mikrokontroller Arduino uno sebagai pusat pengendalian sistem. Setelah dilakukan beberapa kali percobaan pada alat ini, semua komponen dan sistem kerja alat ini mampu bekerja sesuai dengan tujuan penelitian. Penerapan sistem otomatis penambahan cairan nutrisi pada tanaman hidroponik dapat mempermudah petani dalam hal perawatan dan pemantauan tanaman hidroponik tersebut.

Kata kunci- Hidroponik, Electro Conductivity (EC), Arduino Uno, Level Air, Solenoid Valve

\section{Pendahuluan}

Pertanian merupakan salah satu sektor yang penting bagi kehidupan masyarakat Indonesia. Sektor ini berperan sebagai penunjang ketersediaan pangan bagi masyarakat[1]. Sebagian besar lahan di indonesia digunakan untuk proses produksi pertanian. Namun saat ini, sebagian lahan pertanian dialihfungsikan untuk yang lain, sehingga menyebabkan kekurangan ketersediaan lahan pangan[2]. Kondisi lahan pertanian yang semakin terbatas sementara semakin meningkatnya pangan yang dibutuhkan masyarakat, maka diperlukan solusi yang dapat mengatasi masalah tersebut[3].

Seiring dengan perkembangan teknologi, sektor pertanian juga ikut mengalami perkembangan. Salah satu perkembangannya adalah pola cocok tanam tanpa media tanah[4]. Pola cocok tanam ini dikenal dengan nama Hidroponik. Hidroponik itu sendiri merupakan solusi dibidang pertanian dengan menggunakan teknologi sederhana untuk memudahkan masyarakat dalam bercocok tanam karena hidroponik ini merupakan pola cocok tanam tanpa media tanah dan memberdayakan air[5]. Dengan menerapkan sistem hidroponik ini maka dapat mengatasi terjadinya kekurangan nutrisi dan air pada tandon yang akan di sirkulasikan secara terus menerus selama 24 jam[6].

Dalam sistem hidroponik, konsentrasi larutan nutrisi merupakan salah satu parameter yang menentukan kualitas dan hasil panen tanaman[7]. Konsentrasi larutan nutrisi tersebut direpresentasikan dengan nilai electrical conductivity (EC)[8]. Perubahan kadar larutan nutrisi dan level air pada tandon sangat mempengaruhi pertumbuhan tanaman. Bila kita tidak teliti dan pantau secara rutin dan berkala, dapat mengakibatkan pertumbuhan tanaman yang tidak optimal pada kualitas tanaman sayur[9]. Sehingga untuk mempermudah pengelolaan kadar larutan nutrisi dan level air pada tandon dirancanglah sebuah sistem pengontrolan electro conductivity (EC) pada larutan nutrisi hidroponik berbasis arduino[10]. 


\section{Metode}

Metode yang digunakan dalam tugas akhir ini yaitu membuat alat pengontrolan electro conductivity pada larutan nutrisi hidroponik berbasis arduino serta membuat perancangan hardware maupun software.

\section{A. Blok Diagram}

Secara umum blok diagram dari alat pengontrolan electro conductivity pada larutan nutrisi hidroponik berbasis Arduino dijelaskan pada gambar 1 .

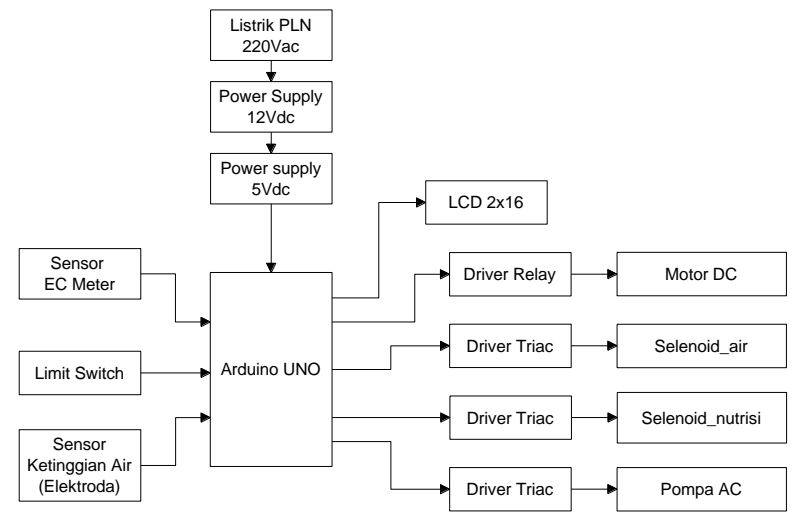

Gambar 1. Blok Diagram Keseluruhan

Berdasarkan blok diagram keseluruhan sistem di atas, fungsi dari masing-masing blok diagram sebagai berikut:

1. Arduino Uno merupakan bagian yang berfungsi untuk memproses input yang dimasukan dan menghasilkan output berupa aktifasi pada alat pengontrolan electro conductivity pada larutan nutrisi hidroponik berbasis Arduino.

2. Sensor EC merupakan sensor yang digunakan untuk mengukur dan mendeteksi cairan nutrisi atau konduktivitas listrik dari cairan yang ada di dalam tandon air yang telah tercampur dengan larutan nutrisi hidroponik tersebut.

3. Sensor Elektroda merupakan input yang difungsikan sebagai media pendeteksi adanya air atau tidak pada tandon air yang telah diberi batasan air pada tandon tersebut.

4. Selenoid_nutrisi berfungsi sebagai penggerak untuk membuka dan menutup katub pada wadah cairan nutrisi.

5. Selenoid_air berfungsi sebagai penggerak untuk membukan dan menutup katub pada wadah air.

6. Limit Switch ini berfungsi untuk memberhentikan ketika mekanik pada sensor kembali seperti posisi semula.

7. Motor DC berfungsi sebagai media penggerak dalam menaikan dan menurunkan pada mekanik yang ditempatkan sensor dalam membaca kadar nutrisi didalam wadah penampung.

8. Pompa AC berfungsi sebagai penggerak untuk mengalirkan air yang telah tercampur cairan nutrisi makanan ke dalam wadah atau tempat tanaman diletakan.

\section{B. Flowchart}

Prinsip kerja pada pengontrolan electro conductivity pada larutan nutrisi hidroponik berbasis Arduino dijelaskan melalui suatu gambar atau bagan urutan perancangan program. Flowchart untuk pengontrolan electro conductivity larutan nutrisi hidroponik ini ditunjukkan pada gambar 2.

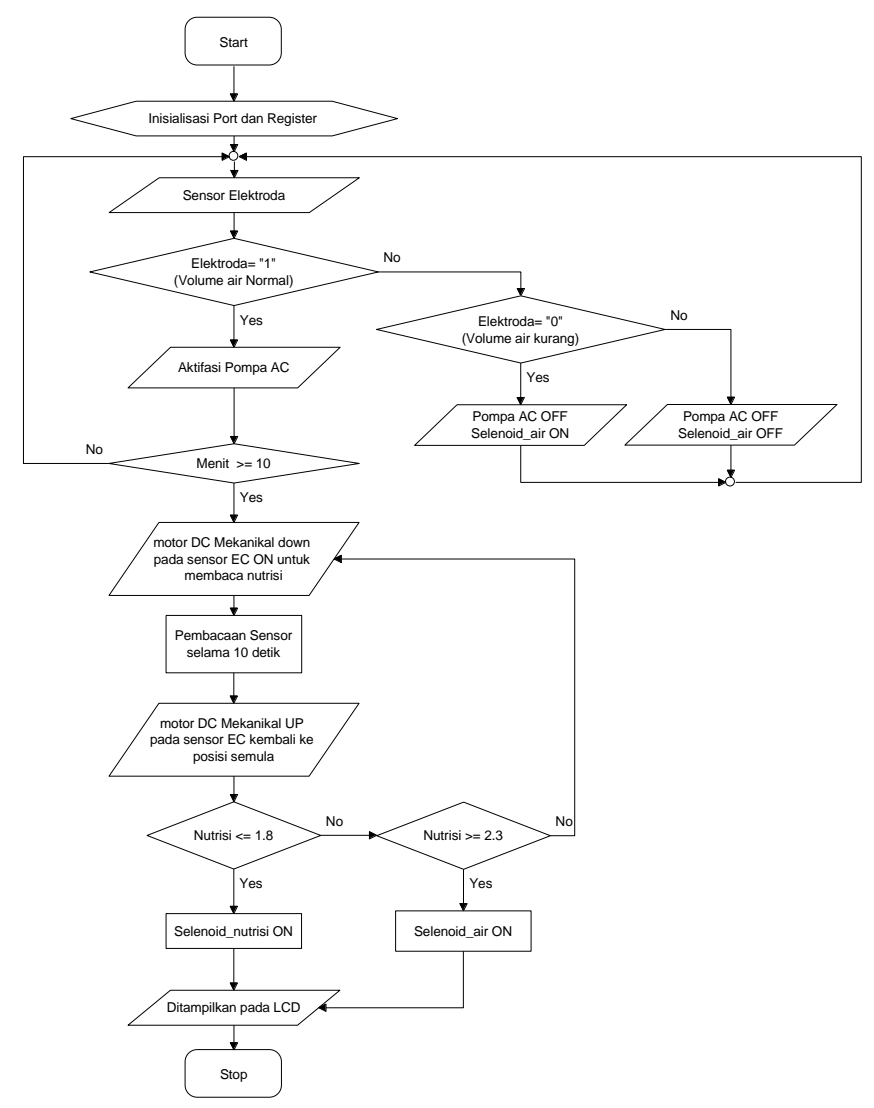

Gambar 2. Flowchart Keseluruhan

Pada gambar flowchart diatas menjelaskan diagram alur kerja prinsip kerja alat secara keseluruhan. Flowchart menunjukan secara jelas arus pengendalian algoritma, yaitu bagaimana rangkaian pelaksanaan kegiatan yang menggambarkan suatu tahapan penyelesaian masalah secara jelas. Pada gambar flowchart diatas merupakan flowchart atau diagram alur cara kerja alat secara keseluruhan, Sistem diawali dengan inisialisasi port, kemudian sistem akan mendeteksi masing-masing keadaan.

\section{Perancangan Hardware}

Perancangan hardware merupakan suatu tahanpan proses yang sangat penting dalam pembuatan suatu perangkat keras. Dengan adanya perancangan hardware pada tugas akhir ini maka sistem alat tersebut dapat diuji bahwa alat ini dapat bekerja dengan baik sesuai dengan perancangannya. Bentuk rancangan fisik alat dapat dilihat pada gambar 3 dibawah ini. 


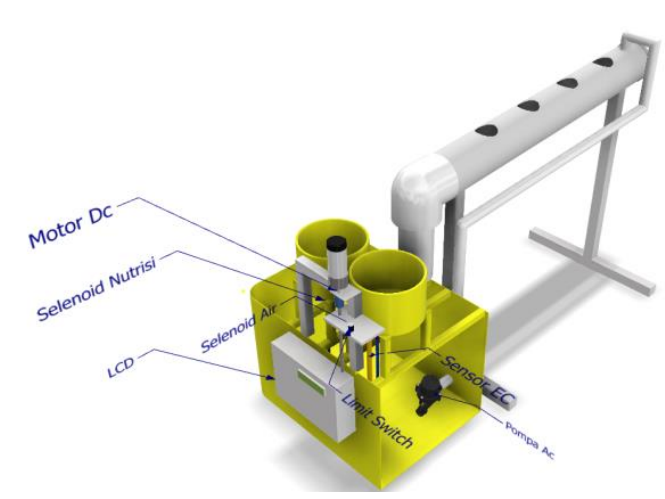

Gambar 3. Rancangan Bentuk Fisik Alat

\section{Perancangan Software}

Perancangan software pada tugas akhir ini menggunakan software Arduino IDE (Integrated Development Environment) yang menggunakan bahasa $\mathrm{C}$ sebagai bahasa pemrogramannya, software ini merupakan software bawaan dari mikrokontroler arduino yang dapat mengendalikan seluruh sistem kerja alat. Pada alat ini memiliki input dan output yang memiliki fungsi berbeda setiap komponennya. Pada software arduino terdapat compile dan upload yang akan mengkomunikasikan mikrokontroler arduino dan input pada alat..

\section{Hasil dan Pembahasan}

Pada bagian ini menjelaskan suatu peralatan atau program dapat bekerja dengan baik apabila telah disertai dengan pembuktian terhadap fungsi kerja dari peralatan tersebut. Pengujian alat pengontrolan electro conductivity larutan nutrisi hidroponik ini meliputi pengujian sensor EC yang berfungsi untuk mengukur nilai EC pada larutan nutrisi tersebut. Pengujian selenoid pada wadah nutrisi dan pada wadah air, yang tiap-tiap selenoidnya akan aktif membuka katup dan mengalirkan air atau nutrisi ke wadah penampung. Dan pengujian sensor elektroda yang diletakkan pada wadah penampung, sensor elektroda akan mendeteksi adanya air atau tidak pada wadah penampung tersebut.

\section{A. Pengujian Rangkaian Sensor EC}

Pengujian sensor EC Meter dilakukan untuk mengukur kadar larutan nutrisi didalam cairan yang mengalir ketanaman hidrophonik pada setiap jamnya. Ketika dilakukan pengujian nilai yang dideteksi sensor akan tampil pada LCD dapat dilihat pada gambar 4. Hasil pengujian sensor EC Meter menampilkan nilai kandungan nutrisi didalam lauran yang telah tercampur dengan air yang dialirkan kedalam pipa untuk tanaman hidrophonik.

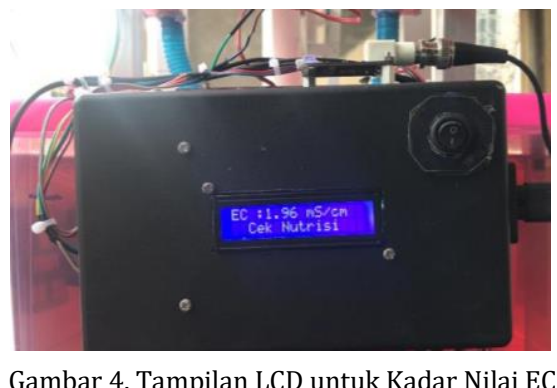

Pengujian sensor EC akan dilakukan menggunakan sensor SKU DFR0300 dan sebagai pembanding, penulis menggunakan EC Meter untuk pengujian sebenarnya. Perbandingan pengujian sensor EC dan EC meter dapat dilihat pada tabel 1. Parameter yang diukur dari pengujian ini adalah error untuk mendapatkan keakuratan dari sensor.

Untuk mengukur percent error dari pengujian ini yaitu dengan menggunakan rumus,

$\%$ Error $=\left|\frac{(\text { Nilai EC Meter-Nilai Sensor EC })}{\text { Nilai EC Meter }}\right| \times 100 \%$

\begin{tabular}{|c|c|c|c|c|}
\hline \multirow{2}{*}{$\begin{array}{c}\text { Hari } \\
\text { ke- }\end{array}$} & Jam & $\begin{array}{c}\text { Nilai } \\
\text { Sensor EC } \\
\text { (milisieme } \\
\text { ns) }\end{array}$ & $\begin{array}{c}\text { Nilai EC } \\
\text { Meter } \\
\text { (milisieme } \\
\text { ns) }\end{array}$ & $\begin{array}{c}\text { Percent Error } \\
\text { (\%) }\end{array}$ \\
\hline \multirow{2}{*}{1} & 09.00 & 1.97 & 2.20 & 0,104545455 \\
\cline { 2 - 5 } & 17.00 & 1.96 & 2.18 & 0,100917431 \\
\hline \multirow{2}{*}{2} & 09.45 & 1.93 & 2.14 & 0,098130841 \\
\cline { 2 - 5 } & 17.20 & 1.91 & 2.11 & 0,09478673 \\
\hline \multirow{2}{*}{3} & 09.25 & 1.89 & 2.09 & 0,09569378 \\
\cline { 2 - 5 } & 18.10 & 1.87 & 2.08 & 0,100961538 \\
\hline \multirow{2}{*}{4} & 08.10 & 1.85 & 2.05 & 0,097560976 \\
\cline { 2 - 5 } & 17.13 & 1.85 & 2.05 & 0,097560976 \\
\hline \multirow{2}{*}{5} & 09.14 & 1.86 & 2.06 & 0,097087379 \\
\cline { 2 - 5 } & 17.40 & 1.87 & 2.08 & 0,100961538 \\
\hline \multirow{2}{*}{6} & 08.50 & 1.85 & 2.05 & 0,097560976 \\
\cline { 2 - 5 } & 17.25 & 1.88 & 2.09 & 0,100478469 \\
\hline \multirow{2}{*}{7} & 08.45 & 1.88 & 2.09 & 0,100478469 \\
\cline { 2 - 5 } & 16.55 & 1.87 & 2.08 & 0,100961538 \\
\hline \multirow{2}{*}{8} & 08.15 & 1.85 & 2.05 & 0,097560976 \\
\cline { 2 - 5 } & 17.30 & 1.86 & 2.06 & 0,097087379 \\
\hline \multirow{2}{*}{9} & 09.25 & 1.85 & 2.05 & 0,097560976 \\
\cline { 2 - 5 } & 18.04 & 1.86 & 2.07 & 0,101449275 \\
\hline \multirow{2}{*}{10} & 09.14 & 1.83 & 2.00 & 0,085 \\
\cline { 2 - 5 } & 17.33 & 1.85 & 2.01 & 0,07960199 \\
\hline \multirow{2}{*}{11} & 09.45 & 1.86 & 2.02 & 0,079207921 \\
\cline { 2 - 5 } & 16.35 & 1.85 & 2.02 & 0,084158416 \\
\hline \multirow{2}{*}{12} & 08.38 & 1.87 & 2.07 & 0,096618357 \\
\cline { 2 - 5 } & 16.57 & 1.85 & 2.03 & 0,088669951 \\
\hline \multirow{2}{*}{13} & 09.15 & 1.86 & 2.03 & 0,083743842 \\
\cline { 2 - 5 } & 17.18 & 1.85 & 2.03 & 0,088669951 \\
\hline \multirow{2}{*}{14} & 08.33 & 1.86 & 2.04 & 0,088235294 \\
\cline { 2 - 5 } & 18.15 & 1.84 & 2.02 & 0,089108911 \\
\hline & & Rata-rata Error & & 0,094441 \\
\hline
\end{tabular}

Berdasarkan pengujian yang telah dilakukan, terlihat bahwa sensor EC SKU DFR0300 dapat bekerja dengan baik sebagai pengukuran kadar nilai EC pada larutan nutrisi hidroponik. Dari tabel diatas rata-rata akurasi percent error dari sensor EC SKU DFR0300 yaitu sebesar 99,905559\%. 


\section{B. Pengujian Penambahan Air pada Wadah Penampung}

Pengujian penambahan air pada wadah penampung ini berfungsi untuk proses penambahan air pada wadah penampung jika level air pada wadah tersebut dibawah batas sensor elektroda yang berfungsi untuk mendeteksi batas air. Sensor elektroda tersebut diletakan pada batas level air yang diingkan pada wadah penampung tersebut. Jika, sensor elektroda tersebut tidak mendeteksi adanya air lagi, maka selenoid valve akan membuka katup pada wadah air dan mengalirkan air ke wadah penampung, penambahan air tersebut selama 1 menit.

Tabel 2. Hasil Pengujian Penambahan Air

\begin{tabular}{|l|l|l|}
\hline $\begin{array}{c}\text { Ketinggian } \\
\text { Air }\end{array}$ & \multicolumn{1}{|c|}{$\begin{array}{c}\text { Sensor } \\
\text { Elektroda }\end{array}$} & \multicolumn{1}{|c|}{ Keterangan } \\
\hline $1 \mathrm{~cm}$ & Elektroda '1' & Selenoid_air ON \\
\hline $2 \mathrm{~cm}$ & Elektroda '1' & Selenoid_air ON \\
\hline $3 \mathrm{~cm}$ & Elektroda '1' & Selenoid_air ON \\
\hline $4 \mathrm{~cm}$ & Elektroda '1' & Selenoid_air ON \\
\hline $5 \mathrm{~cm}$ & Elektroda '0' & Selenoid_air OFF \\
\hline $6 \mathrm{~cm}$ & Elektroda '0' & Selenoid_air OFF \\
\hline $7 \mathrm{~cm}$ & Elektroda '0' & Selenoid_air OFF \\
\hline $8 \mathrm{~cm}$ & Elektroda '0' & Selenoid_air OFF \\
\hline $9 \mathrm{~cm}$ & Elektroda '0' & Selenoid_air OFF \\
\hline $10 \mathrm{~cm}$ & Elektroda '0' & Selenoid_air OFF \\
\hline $11 \mathrm{~cm}$ & Elektroda '0' & Selenoid_air OFF \\
\hline $12 \mathrm{~cm}$ & Elektroda '0' & Selenoid_air OFF \\
\hline
\end{tabular}

Berdasarkan pengujian yang telah dilakukan pada proses penambahan air tersebut, ketika ketinggian airnya dibawah $5 \mathrm{~cm}$ maka selenoid_air akan aktif membuka katup wadah air dan mengalirkannya ke wadah penampung selama 1 menit. Jika ketinggian air diatas $5 \mathrm{~cm}$, tidak ada penambahan air karena sensor elektroda tersebut masih mendeteksi adanya air pada batas air yang diinginkan. Komponen yang digunakan dapat bekerja dengan baik sehingga proses penambahan air pada wadah penampung tersebut dapat berjalan dengan baik.

\section{Pengujian Penambahan Cairan Nutrisi dan Air}

Pengujian penambahan cairan nutrisi ini berfungsi untuk proses penambahan cairan nutrisi jika pada wadah nutrisi nilai EC nya sudah berkurang. Pada proses ini, setiap sepuluh menit sekali sensor akan mendeteksi nilai EC pada cairan nutrisi pada wadah tersebut, jika nilai EC pada cairan nutrisi di wadah kurang dari batas nilai EC tersebut, maka selenoid pada wadah nutrisi akan aktif dan mengalirkan cairan nutrisi tersebut ke wadah penampung selama 20 detik hingga mencapai batas nilai EC tersebut. Dan begitu sebaliknya, jika nilai EC pada cairan nutrisi di wadah berlebih dari batasnya, maka selenoid pada wadah air akan aktif dan mengalirkan air ke wadah penampung selama 20 detik hingga mencapai batas nilai EC tersebut. Pada pengujian ini dimulai dari nilai EC pada batas 1,5 sampai 2,5 untuk melakukan pengujian pada proses penambahan cairan nutrisi atau air. Pengujian penambahan cairan nutrisi dapat dilihat pada tabel 3 .

Tabel 3.

\begin{tabular}{|c|c|c|}
\hline SetPoint & $\begin{array}{c}\text { Nilai EC } \\
\text { (mikrosiemens) }\end{array}$ & Keterangan \\
\hline \multirow{10}{*}{$1.8-2.3$} & 1.55 & $\begin{array}{c}\text { Selenoid_air OFF } \\
\text { Selenoid_nutrisi ON }\end{array}$ \\
\hline & 1.66 & $\begin{array}{c}\text { Selenoid_air OFF } \\
\text { Selenoid_nutrisi ON }\end{array}$ \\
\hline & 1.78 & $\begin{array}{c}\text { Selenoid_air OFF } \\
\text { Selenoid_nutrisi ON }\end{array}$ \\
\hline & 1.81 & $\begin{array}{c}\text { Selenoid_air OFF } \\
\text { Selenoid_nutrisi OFF }\end{array}$ \\
\hline & 1.93 & $\begin{array}{c}\text { Selenoid_air OFF } \\
\text { Selenoid_nutrisi OFF }\end{array}$ \\
\hline & 2.05 & $\begin{array}{c}\text { Selenoid_air OFF } \\
\text { Selenoid_nutrisi OFF }\end{array}$ \\
\hline & 2.14 & $\begin{array}{c}\text { Selenoid_air OFF } \\
\text { Selenoid_nutrisi OFF }\end{array}$ \\
\hline & 2.28 & $\begin{array}{c}\text { Selenoid_air OFF } \\
\text { Selenoid_nutrisi OFF }\end{array}$ \\
\hline & 2.36 & $\begin{array}{c}\text { Selenoid_air ON } \\
\text { Selenoid_nutrisi OFF }\end{array}$ \\
\hline & 2.5 & $\begin{array}{c}\text { Selenoid_air ON } \\
\text { Selenoid_nutrisi OFF }\end{array}$ \\
\hline
\end{tabular}

Berdasarkan pengujian yang telah dilakukan pada proses penambahan cairan nutrisi, pada saat nilai EC kurang dari batasnya, selenoid_nutrisi membuka katup dan mengalirkan cairan nutrisi ke wadah penampung selama 20 detik. Dan jika nilai EC pada nutrisi lebih dari batas yang diinginkan, maka selenoid_air akan membuka katup dan mengalirkan air ke wadah penampung selama 20 detik. Masing-masing komponen dapat bekerja dengan baik sebagaimana fungsinya.

\section{KESIMPULAN}

Berdasarkan hasil dari perancangan dan pengujian pada sistem pengontrol electro conductivity pada larutan nutrisi hidroponik berbasis Arduino ini dapat disimpulkan bahwa alat ini mampu bekerja dengan baik sesuai dengan rancangan sistem kerja alat tersebut. Sitem kerja alat ini meliputi penambahan cairan nutrisi, penambahan air, dan mendeteksi nilai kadar EC pada larutan nutrisi tersebut. Secara keseluruhan sistem kerja alat, alat ini mampu memantau dan mengontrol nilai kadar EC pada larutan nutrisi hidroponik sesuai dengan tujuan pembuatan tugas akhir ini.

\section{REFERENSI}

[1] S. Ekawati, "Rancang Bangun Sistem Monitoring Nutrisi Tanaman Hidroponik Menggunakan Arduino Uno Berbasis Web Server (Studi Kasus Kusuma Agrowisata)," Repos. Institusi UMM, 2015.

[2] M. B. Ridwan, "Sistem Monitoring Tanaman Hidroponik Dengan Sensor PH, Suhu Air Dan Pemupukan Berbasis Internet of Thing," $J$. TeknoSAINS FTIE UTY, 2019.

[3] R. Ulfah, "Pengukur Electro Conductivity pada Larutan Nutrisi Hidroponik Berbasis 
Mikrokontroler Atmega8535," Repos.

Institusi USU, 2018.

[4] G. Pamungkas, A. Z. Purwalaksana, M. Djamal, and N.

S. Amina, "Rancang Bangun Hidroponik Sistem Nutrient Film Technique Otomatis Berbasis Arduino," Pros. Snips, pp. 45-51, 2017.

[5] P. N. Safiroh, "Sistem Pengendalian Kadar pH dan Penyiraman Tanaman Hidroponik Wick System," Digilib Unila (Digital Repos. Unila), no. February, pp. 1-9, 2019, doi:.1037//0033-2909.I26.1.78.

[6] M. Gregoryan, J. Andjarwirawan, and R. Lim, "Sistem Kontrol dan Monitoring Ph Air serta Kepekatan Nutrisi pada Budidaya Hidroponik Jenis Sayur dengan Teknik Deep Flow Techcnique," J. Infra, vol. 7, no. 2, pp. 1-6, 2019.

[7] G. G. Heliadi, M. R. Kirom, and A. Suhendi, "Monitoring dan Kontrol Nutrisi pada Sistem Hidroponik NFT Berbasis Konduktifitas Elektrik," $e$ Proceeding Eng., vol. 5, no. 1, pp. 885-893, 2018.

[8] Z. Buana, "Sistem Pemantauan Tanaman Sayur Dengan Media Tanam Hidroponik Menggunakan Arduino," JTEV (Jurnal Tek. Elektro dan Vokasional), vol. V, no. 1, pp. 74-80, 2019.

[9] A. Prasetyo, U. Nurhasan, and G. Lazuardi, "Implementasi Iot Pada Sistem Monitoring Dan Pengendali Sirkulasi Air Tanaman Hidroponik," J. Inform. Polinema, vol. 5, no. 1, p. 31, 2018, doi: 10.33795/jip.v5i1.241.

[10] D. Pancawati and A. Yulianto, "Implementasi Fuzzy Logic Controller untuk Mengatur Ph Nutrisi pada Sistem Hidroponik Nutrient Film Technique (NFT)," J. Nas. Tek. Elektro, vol. 5, no. 2, p. 278, 2016, doi: 10.25077/jnte.v5n2.284.2016.

\section{Biodata Penulis}

Syafa Aprillia, Lahir di langsa, 29 April 1998. Menyelesaikan studi DIV Teknik Elektro Industri pada Jurusan Teknik Elektro Fakultas Teknik Universitas Negeri Padang.

Dwiprima Elvanny Myori, S.Si, M.Si, Lahir di Palembang, 1 November 1988. Menyelesaikan studi S1 Matematika di Universitas Andalas pada tahun 2010. Pendidikan S2 Matematika di Universitas Andalas pada tahun 2012. Saat ini terdaftar sebagai dosen pengajar pada Jurusan Teknik Elektro Universitas Negeri Padang. 